Transportation Research Forum

Modeling Willingness-to-Pay Values for Rural Bus Attributes Under Different Trip Purposes Author(s): C. V. Phanikumar and Bhargab Maitra

Source: Journal of the Transportation Research Forum, Vol. 45, No. 2 (Summer 2006), pp. 31-44

Published by: Transportation Research Forum

Stable URL: http://www.trforum.org/journal

The Transportation Research Forum, founded in 1958, is an independent, nonprofit organization of transportation professionals who conduct, use, and benefit from research. Its purpose is to provide an impartial meeting ground for carriers, shippers, government officials, consultants, university researchers, suppliers, and others seeking exchange of information and ideas related to both passenger and freight transportation. More information on the Transportation Research Forum can be found on the Web at www.trforum.org. 


\section{Modeling Willingness-to-Pay Values for Rural Bus Attributes Under Different Trip Purposes}

\section{by C. V. Phanikumar and Bhargab Maitra}

The paper focuses on estimating willingness-to-pay (WTP) values associated with attributes of bus travel in rural regions of a developing country. Using stated choice data, Multinomial Logit (MNL) and Random Parameter Logit (RPL) models with constrained triangular distribution for random parameters are developed for various trip purposes. WTP values are estimated for travel time, travel discomfort and headway of service. It is found that WTP values of job trips are highest among all trips, followed by recreation and business trips; and the values for discomfort are found to be highly sensitive to trip purpose. Also, it is found that the MNL model underestimated WTP values more than the RPL model.

\section{INTRODUCTION}

In India and other developing countries, a majority of the population is located in rural and suburban areas. Personal vehicle ownership is generally low in rural areas and, therefore, rural passengers are essentially captive to the bus transportation system. Rural bus services generally have low travel speed, longer headways, high discomfort level (i.e., crowding inside buses) and low reliability. Improvement in rural bus service may be achieved by suitably changing one or more of its attributes, such as travel speed, frequency, comfort, etc. But, improvements in bus services are often associated with an increase in fare. For judicious improvement planning of existing bus services and evaluation of user benefits, it is necessary to understand the values trip makers place on different attributes of travel.

The literature shows several willingness-to-pay (WTP) values in the context of transport and non-transport improvements in developed countries (Hensher 1994; Jose Holguin-Veras 2002; Hensher and Greene 2001; Adamowicz et al. 1994; Carlsson et al. 2003; Onyango 2004). A large number of works have reported WTP values for travel time savings in developed countries (Algers et. al. 1998; Greene et. al. 2005; Hensher 2001a,b; Hensher and Sullivan 2003; Hess et al. 2005; Carlsson 1999; Cherchil and Polak 2005). WTP values for travel time savings in developing countries have been reported by Farhad and Kirit (2004) for rural areas of Bangladesh, I. T. Transport (2004) for rural regions of Tanzania \& Ghana, Kumarage (2005) for Colombo, Sri Lanka, and Mumbai Metro Planning Group (1997); and Praveen and Rao (2002) for Mumbai, India. In general, there is very limited information available in the literature about WTP values for rural bus attributes in developing countries such as India.

The objective of this paper is to model WTP values considering both quantitative and qualitative attributes of rural bus service in a developing country context, and the variation of WTP values with trip purpose. The empirical study is a rural bus route connecting a district headquarter (Midnapur) and a tourist place (Digha) in West Bengal, India. Travel demand along this route is largely served by bus service, which takes about five hours to cover a distance of 142 kilometers and serves about 35 intermediate stops.

The paper is organized as follows: The methodology section introduces preferences and model specifications and it is followed by questionnaire design, data collection, and model estimation respectively. Next, the results of the analysis and conclusion are presented. 
Willingness-to-Pay Values

\section{METHODOLOGY}

\section{Approach}

Revealed Preference (RP) or Stated Preference (SP) data have been used in diverse fields for estimating the WTP values (Adamowicz et al. 1994; Bates 1982; Kroes \& Sheldon 1988; Louviere 1988; Hensher 1994; Jose Holguin-Veras 2002). At times, RP data may be inappropriate as they cannot accommodate non-existing attributes or variability of attributes which, in turn, does not permit establishing their influences. On the other hand, SP data facilitate inclusion of hypothetical attributes and variability of attributes. Stated choice (SC) experiments provide a framework for studying the relative marginal disutility of variations in attributes, and their potential correlations (Louviere et al. 2000). Stated Choice (SC) methods have a strong theoretical foundation based on economic theory, and are an established approach for understanding and predicting consumer tradeoffs and choices in marketing research. SC methods are used extensively to model the behavior of individuals (Hensher and Greene 2001; Hensher 2001; Hensher and Sullivan 2003; Carlsson et al. 2003; Onyango 2004). In the present paper, the SC method is adopted to elicit preferences by generating hypothetical profiles using various attributes and their levels. These profiles are presented along with a base profile (revealed data) to respondents in the form of a choice set, and 'choice' responses are utilized to estimate the WTP values.

Generally, SP and/or RP data are analyzed using traditional Multinomial Logit (MNL) models due to simplicity in estimation. However, the MNL model imposes some restrictions such as independence of irrelevant alternatives (IIA). Modifications to the MNL models to reduce the influence of these restrictions lead to Random Parameter Logit (RPL) or Mixed Logit (ML). For the development of RPL models, it is necessary to assume suitable distributions for random parameters. Different distributions for random parameters such as normal, lognormal, uniform, and triangular have been attempted by researchers while developing RPL models (Algers et al. 1998; Hensher 2001a; Hensher and Greene 2001). The lognormal distribution is suitable if the mean of the random parameter needs to be of specific (non-negative) sign. However, a long upper tail of the lognormal distribution results in extremely high WTP values. A uniform distribution with a $(0,1)$ bound is suitable for dummy variables. The triangular distribution where the density function looks like a tent with a peak in the center and dropping off linearly on both sides of the center is advantageous over normal or lognormal distributions due to its bounded nature. However, like normal or uniform distribution, triangular distribution also has the disadvantage of producing wrong signs for some shares due to spread or standard deviation. It is possible to overcome the disadvantage of triangular distribution by imposing a constraint on the spread (Hensher and Green 2001). When the mean and the spread are equal, the constrained distribution has a peak in the density function with two endpoints of the distribution fixed at zero and two times the standard deviation, so that there is no free variance (scaling) parameter.

In this paper, constrained triangular distribution of random parameters is assumed because of the following advantages: First, constrained triangular distribution assures that the sign of the mean is the same throughout the sample unlike a normal, lognormal, or triangular distribution, which shows sign reversal for some samples. Second, its estimation of WTP value is simple as the impact of spread is negligible due to equality between the mean and the spread. The ratio of the mean coefficient of any attribute to the mean coefficient of cost directly gives WTP. This is unlike normal or lognormal distributions where the standard deviation or spread has a significant effect on WTP. Lastly, unlike normal or lognormal distributions, the triangular distribution is bounded in nature and results in early convergence.

WTP values may be influenced by one or more socioeconomic attributes, such as age, income, household size, etc. The effect of socioeconomic characteristics on the mean of a random parameter (called 'mean heterogeneity') is investigated with RPL models. 


\section{Econometric Model}

In econometric models based on Random Utility Theory (Thurstone 1927; McFadden 1974), the utility of each element consists of an observed (deterministic) component denoted by $V$ and a random (disturbance) component denoted by $\varepsilon$,

$$
\mathrm{U}=\mathrm{V}+\varepsilon
$$

The deterministic part $V$ is again a function of the observed attributes $(z)$ of the choice as faced by the individual, the observed socioeconomic attributes of the individual $(S)$ and a vector of parameters $(\beta)$. Therefore,

$$
V=V(z, S, \beta)
$$

A probabilistic statement can be made (due to the presence of the random component) as, when an individual ' $n$ ' is facing a choice set, $C_{n}$, consisting of $\mathrm{J}_{\mathrm{n}}$ choices, the choice probability of alternative $\mathrm{i}$ is equal to the probability that the utility of alternative ' $\mathrm{i}$ ', $\mathrm{U}_{\mathrm{in}}$, is greater than or equal to the utilities of all other alternatives in the choice set, i.e.,

$$
\begin{aligned}
& P_{\mathrm{n}}(\mathrm{i})=\operatorname{Pr}\left(U_{\mathrm{in}} \geq U_{\mathrm{jn}}, \text { for all } j € C_{\mathrm{n}}\right) \\
& P_{\mathrm{n}}(\mathrm{i})=\operatorname{Pr}\left(V_{\mathrm{in}}+\varepsilon_{\mathrm{in}} \geq V_{\mathrm{jn}}+\varepsilon_{\mathrm{jn}}, \text { for all } j € C_{\mathrm{n}, j \neq i}\right)
\end{aligned}
$$

Assuming IID (Gumbel distribution) for $\varepsilon$, the probability that an individual chooses $\mathrm{i}$ can be given by the MNL Model (McFadden 1974; Ben-Akiva and Lerman 1985),

$$
P_{n}=\frac{e^{V_{i n}}}{\sum_{j \in j_{n}} e^{V_{i n}}}
$$

This model can be estimated by maximum likelihood techniques and is useful for modeling choice behavior. However, it has several limitations, the most severe of which is the IIA property, which states that a change in the attributes of one alternative changes the probabilities of the other alternatives in proportion. This substitution pattern may not be realistic in all settings. Secondly, the coefficients of all attributes are assumed to be the same for all respondents in a choice experiment, whereas in reality there may be substantial variability in how people respond to attributes. To overcome these limitations, a generalized form of MNL (i.e., a random parameters logit model) is used to account for unobserved heterogeneity.

Let the utility function of alternative i for individual $\mathrm{n}$ be,

$$
\mathrm{U}_{\mathrm{in}}=\beta \mathrm{x}_{\mathrm{in}}+\varepsilon_{\text {in }}=\beta^{\mathrm{I}} \mathrm{x}_{\mathrm{in}}+\hat{\beta}_{n} \mathrm{x}_{\mathrm{in}}+\varepsilon_{\mathrm{in}}
$$

Thus, each individual's coefficient vector $\beta$ is the sum of the population mean $\beta^{\mathrm{I}}$ and individual deviation $\hat{\beta}_{n} . \hat{\beta}_{n} \mathrm{x}_{\mathrm{in}}$ are error components that induce heteroskedasticity and correlation over alternatives in the unobserved portion of the utility. An important implication of the mixed logit specification is that we do not have to assume that the IIA property holds.

Let tastes, $\beta$, vary in the population with a distribution density $f(\beta \mid \theta)$, where $\theta$ is a vector of the true parameters of the taste distribution. If the error terms $\left(\varepsilon_{\text {in }}\right)$ are IID type I extreme value, it is a random parameter logit model (Train 1998). The conditional probability of observing a sequence of choices is the product of the conditional probabilities:

$$
S_{n}\left(\beta_{n}\right)=\prod P\left(k(n, t) t \mid \beta_{n}\right)
$$


Willingness-to-Pay Values

Where $k(n, t)$ denotes the sequence of choices from choice sets that an individual $n$ chooses in situation $t$. In the choice experiment, the sequence of choices is the number of hypothetical choices each respondent makes in the survey. The unconditional probability for a sequence of choices for individual $n$ is then expressed as the integral of the conditional probability in equation (7) over all values of $\beta$ :

$$
P_{n}(\theta)=\int S_{n}(\beta) f(\beta \mid \theta) d \beta
$$

In general, the integral cannot be evaluated analytically, and one has to rely on a simulation method for the probabilities. Here a simulated maximum likelihood estimator, using Halton draws is used (Train 1999). This type of random parameter model is less restrictive than standard conditional logit models. However, these less restrictive models should be applied cautiously. Apart from being more difficult to estimate, the literature shows that the results can be rather sensitive to the distributional assumptions and the number of draws applied in the simulation (Hensher and Greene 2001).

\section{SURVEY INSTRUMENT AND STUDY}

Survey instruments were designed for collecting respondent's trip characteristics, socioeconomic characteristics, and stated preference 'choice' from the choice set. A questionnaire consisting of three parts was designed. The first part was to collect information related to respondent's trip characteristics, such as origin, destination, trip purpose, etc. The second part was to record the respondent's sociodemographic information, such as age, gender, income, etc. The third part was to observe a respondent's 'choice' from the choice sets. Choice sets are prepared using four attributes, each described by four levels.

During preliminary investigation it was observed that journey speeds for buses were low (about $30 \mathrm{kmph}$ ), comfort was less and average headway was about 30 minutes. Therefore, quantitative attributes, such as travel speed (a proxy for in-vehicle travel time), travel cost and headway, and a qualitative attribute, discomfort, were considered for the preparation of choice sets. Each attribute was further described by four levels. The levels of these attributes were decided following discussions with experts and trip makers. The attributes and their corresponding levels used in the study are shown in Table 1.

Table 1: Attributes and Levels

\begin{tabular}{lcccc}
\hline Attributes & Level 1 & Level 2 & Level 3 & Level 4 \\
\hline Discomfort Level & Seating & $\begin{array}{c}\text { Partly Standing } \\
\text { Partly Seating }\end{array}$ & $\begin{array}{c}\text { Stand } \\
\text { Comfortably }\end{array}$ & Stand in Crowd \\
Headway (minutes) & 15 & 30 & 45 & 60 \\
Travel Speed (kph) & 30 & 35 & 40 & 45 \\
Travel Cost (p/km) & 35 & 40 & 45 & 50 \\
\hline
\end{tabular}

$\mathrm{kph}$ - kilometers per hour

$\mathrm{p} / \mathrm{km}$ - paise per kilometer, where paise is India monetary unit

Four attributes with four levels each would produce $4^{4}(256)$ alternatives from full factorial technique. However, it was neither necessary nor practically possible to include all these combinations in the SP experiment. Therefore, some of the choice sets were eliminated using the fractional factorial technique. Fractional factorial orthogonal main effects using SPSS 7.5 (Hensher et al. 2005) produced 16 alternatives. Pairing these 16 alternatives would result in eight choice sets, and evaluating eight choice sets may lead to fatigue and biased responses. To reduce fatigue 
in respondents, these 16 alternatives were randomly grouped into four choice sets, each containing four hypothetical alternatives. A base alternative was also added to each of these four choice sets. As a result, each choice set contained five alternatives of which four alternatives were hypothetical (generated) ones and one was the base (bus) alternative revealed by the respondent. A fixed experiment approach where each respondent faces exactly the same choice sets at exactly the same stage of the choice task was adopted for presenting the choice sets. All the alternatives in a choice set were presented in generic form (i.e., alternative A, alternative B, etc.).

Interviewers were trained in multiple sessions to improve the quality of the work. Interviewers were equipped with information to be incorporated into the SP part of the questionnaire based on the information from the RP part. Along with speed, corresponding travel time between the origin and destination given by each respondent was also presented by the enumerator to improve clarity while obtaining the choices. A sample of an SP choice set is presented in Figure 1.

Figure 1: Sample Choice Set

\begin{tabular}{lccccc}
\hline Attribute & Base & Alternative 1 & Alternative 2 & Alternative 3 & Alternative 4 \\
\hline Comfort & Revealed & Seating & $\begin{array}{c}\text { Standing } \\
\text { Comfortably }\end{array}$ & $\begin{array}{c}\text { Standing } \\
\text { Comfortably }\end{array}$ & $\begin{array}{c}\text { Partly Standing } \\
\text { Partly Seating }\end{array}$ \\
Frequency & Revealed & $30 \mathrm{~min}$. & $15 \mathrm{~min}$ & $45 \mathrm{~min}$ & $60 \mathrm{~min}$ \\
Travel Time & Revealed & $@ 30 \mathrm{kph}$ & $@ 40 \mathrm{kph}$ & $@ 45 \mathrm{kph}$ & $@ 35 \mathrm{kph} \_$ \\
Fare & Revealed & $@ 40 \mathrm{p} / \mathrm{km} \ldots$ & $@ 45 \mathrm{p} / \mathrm{km}$ & $@ 40 \mathrm{p} / \mathrm{km} \_$ & $@ 45 \mathrm{p} / \mathrm{km} \ldots$ \\
Choice & & & & & \\
\hline
\end{tabular}

kph - kilometers per hour

$\mathrm{p} / \mathrm{km}$ - paise per kilometer, where paise is India monetary unit

Face-to-face interviews were carried out at 16 major stops along the route, including market places, banks, schools, recreational spots, bus stops, etc. Respondents were approached randomly (i.e., random sampling). During the study, 750 respondents were approached to participate in the survey and 475 (63\%) gave their consent. Each respondent was requested to provide information related to the most recent trip undertaken, socioeconomic characteristics, and then to choose an alternative from each of the four choice sets. When respondents pick one alternative from a choice set, they are evaluating four alternatives of a choice set and picking one. This means that while choosing one from each of the four choice sets, the respondent evaluates all 16 alternatives. Thus, this not only gave each respondent an opportunity to evaluate all the 16 alternatives, but also enriched the database with more SC observations (than the number of respondents).

\section{DATABASE}

The database includes respondent's socioeconomic characteristics such as age, occupation, personal income, family size, and household income. It also includes trip characteristics such as origin, destination, purpose, duration of the trip, fare paid, and route characteristics such as length of the route, number of bus stops, fare structure, schedule, and the SP 'choice.' Route characteristics and mode characteristics data were collected from secondary sources such as the Regional Transport Authority (RTA) and Transport agencies. From the trip characteristics, trips were classified as business, educational, job, recreation, agriculture and other trips. Though 475 people were interviewed at various locations along the study route, which would have given 1,900 choices, some were removed due to incomplete information. This resulted in only 1,489 refined observations for the purpose of model development. Summary statistics of the information about trip purposes and 
Willingness-to-Pay Values

socioeconomic details including gender, age and household income forming the database for the present work are given in Table 2.

Table 2: Descriptive Statistics of Some Sociodemographic Data

\begin{tabular}{|c|c|}
\hline Variable & Number \\
\hline Observations & 1489 \\
\hline Male & 1209 (80\%) \\
\hline \multirow[t]{4}{*}{ Age } & 0 \\
\hline & 694 \\
\hline & 778 \\
\hline & 17 \\
\hline \multicolumn{2}{|l|}{ Household Income per month } \\
\hline$\leq 5000 \mathrm{INR}(\approx \mathrm{US} \$ 113)$ & 489 \\
\hline 5000-10000 INR $(\approx$ US\$ 113-227) & 515 \\
\hline $10001-15000 \mathrm{INR}(\approx \mathrm{US} \$ 227-341)$ & 238 \\
\hline$\geq 15000 \mathrm{INR}(\approx \mathrm{US} \$ 341)$ & 247 \\
\hline Work Trips & 435 (29.2\%) \\
\hline Business Trips & $332(22.2 \%)$ \\
\hline Recreation Trips & $360(24.3 \%)$ \\
\hline Education Trips & $130(8.7 \%)$ \\
\hline Agriculture Trips & $151(10.1 \%)$ \\
\hline Other Trips & $81(5.4 \%)$ \\
\hline
\end{tabular}

\section{MODEL ESTIMATION}

The refined observations were used to estimate utility models using LIMDEP 8.0 (Green 2002). Models were estimated for total trips as well as trip purposes (i.e., business, educational, job, recreation, agriculture, and others). In each case, both MNL and RPL models were developed. In the development of RPL models, in-vehicle travel time, headway, and levels of comfort were taken as random parameters, while travel cost was considered a fixed (i.e., non-random) parameter. The reasons for keeping the travel cost parameter fixed are: (1) it simplifies the estimation of marginal WTP for other parameters - simple division of the coefficient of attribute by the coefficient of cost, (2) the distribution of the marginal willingness-to-pay for an attribute is simply the distribution of that attribute's coefficient, and (3) to restrict the price variable to be non-positive for all individuals. RPL models were estimated with simulated maximum likelihood using intelligent Halton draws with 500 replications. The MNL and RPL models developed for various trip purposes are presented in Tables 3 through Table 9. For all the RPL models developed and reported in Table 3 through Table 9 , attempts were made to study the influence of socioeconomic characteristics on the mean estimates of random parameters. However, their coefficients were found to be statistically insignificant. Following Hensher et al. (2005) we removed the variables with insignificant coefficients and reestimated the models. 


\section{RESULTS AND DISCUSSION}

Table 3 through Table 9 show the results of MNL and RPL models for all trips as well as for different trip purposes. It is observed that the signs of the parameters are as expected and in agreement with the actual condition of the study route. The negative signs of the parameters indicate that utility decreases with an increase in the magnitude of the respective attributes. It is evident from the t-ratios that the parameter estimates are statistically significant. The overall goodness of fit is considered on the basis of $\rho^{2}$. A value of the $\rho^{2}$ between 0.2 and 0.4 indicates acceptable model fit (Louviere et al. 2000). The $\rho^{2}$ values indicate that these models are good in fit. The $\rho^{2}$ value also improved from MNL to RPL models.

The interpretation of the coefficients is not straightforward except for significance. Therefore, the marginal rate of substitution between each attribute and cost is calculated by taking the ratio of the coefficient of the attribute to that of cost. The resulting ratios can be interpreted as marginal WTP for a unit change in each attribute under consideration. In the cases of qualitative attributes, estimation of WTP values is based on rescaled coefficients of the levels, where the last level is considered the reference level (set to zero), and the estimated values are with reference to the last level (i.e., for a shift from last level to the level under consideration). The marginal WTP estimates from the MNL and RPL models are shown in Table 10 for various attributes and for different trip purposes. The value of headway is estimated for average trip lengths of respective trip purposes.

It is observed from Table 10 that for the total sample, trip makers' marginal WTP for in-vehicle travel time is about 2.7 times that of headway in both the MNL and RPL estimates. However, the RPL model is found to produce WTP values that are 43\% higher for in-vehicle travel time and 31\% higher for headway than the corresponding values from the MNL model. The marginal WTP values increased consistently for changing from comfortable standing, partly standing, and partly seating, and comfortable seating in both the MNL and RPL models. The difference between the RPL and MNL estimates of WTP for comfort in Table 10 is from 41\% to 97\%, with the RPL model producing higher WTP values.

For business trip makers, the WTP values for in-vehicle travel time are 2.7 to 3.3 times those of headway. For discomfort, changing from comfortable standing, partly standing, partly seating, and comfortable seating increases WTP values as expected.

Job trip makers value travel time about 2.5 times higher than waiting time. For them, the WTP values produced by the RPL model for discomfort are about $48 \%$ to $94 \%$ higher than those from the MNL model estimates in Table 10.

For recreation trip makers, the subjective value of travel time from the RPL model is $41 \%$ more than that from the MNL model, while the WTP value associated with headway is $32 \%$ higher. In-vehicle travel time for recreational trip makers is valued nearly twice as much as headway. For discomfort, the WTP values from the RPL model for these trip makers are about $40 \%$ to $80 \%$ higher than those from MNL model.

Agricultural, educational, and other trip makers value in-vehicle travel time about 3 to 4 times the value of headway. The WTP values produced for discomfort by the RPL model range between 1.4 to 2 times the values from the MNL model for agricultural trip makers. On the other hand, the WTP values are 1.3 to 2.2 times the values for other trip makers, and 1.2 to 1.5 times the values for educational trip makers.

For all trip makers, travel time is valued at 2 to 3 times as much as headways are valued. This is in contrast to observations in developed countries where waiting time usually is valued higher (almost double) than travel time. This high value of travel time may be attributed to the poor comfort conditions inside the vehicles and the longer journey times. A comparison of willingness-to-pay values shows that it is sensitive to trip purpose. Discomfort, for example, is highly sensitive to trip purpose with the highest value of each level being approximately 3.5 to 5.5 times its lowest value. Willingness-to-pay value for travel time and headways are also sensitive to trip purpose, varying from 2.7 to 3.3 and 3.5 to 4.7 times their lowest values respectively. Job trips have the 
Willingness-to-Pay Values

highest willingness-to-pay values for all attributes, and this may be attributed to the prevailing poor operating conditions in terms of long travel times and crowding experienced daily by travelers. Recreational trips, which generally are pleasure trips, also have high values for discomfort as people making such trips prefer to have highest comfort. For agriculture and other trips, predominantly made by low income groups, all the attributes have relatively low values.

A comparison of WTP estimates in Table 10 from MNL models and RPL models indicates that the MNL models gives lower WTP values in all the cases. The average gain in trip purpose WTP estimates, from RPL models, for in-vehicle travel time is about 35\%; and for headway it is about 22\%. Similar observations are reported by Bhatt (1998) and Hensher (2001) in developed country context.

Table 3: MNL and RPL Model Estimates for Total Trips

\begin{tabular}{|c|c|c|c|c|}
\hline \multirow[b]{2}{*}{ Attribute } & \multicolumn{2}{|c|}{ MNL } & \multicolumn{2}{|c|}{ RPL } \\
\hline & Coefficient & Abs. t-ratio & Coefficient & Abs. t-ratio \\
\hline \multicolumn{5}{|l|}{ Random Parameters } \\
\hline Travel Time & -5.540 & 19.35 & -6.563 & 14.88 \\
\hline Service Headway & -0.047 & 10.24 & -0.052 & 8.72 \\
\hline Comfortable seating & 1.195 & 17.44 & 1.466 & 13.75 \\
\hline Part seating & 0.548 & 7.23 & 0.476 & 5.59 \\
\hline Comfortable standing & -0.423 & 2.79 & -0.238 & 1.50 \\
\hline \multicolumn{5}{|l|}{ Fixed Parameters } \\
\hline Travel Cost & -0.103 & 4.36 & -0.086 & 3.51 \\
\hline \multicolumn{5}{|c|}{ Random parameter spread } \\
\hline Travel Time & - & - & 6.563 & 14.88 \\
\hline Service Headway & - & - & 0.052 & 8.72 \\
\hline Comfortable seating & - & - & 1.466 & 13.75 \\
\hline Part seating & - & - & 0.476 & 5.59 \\
\hline Comfortable standing & - & - & 0.238 & 1.50 \\
\hline Observations & \multicolumn{2}{|c|}{1489} & \multicolumn{2}{|c|}{1489} \\
\hline Log Likelihood & \multicolumn{2}{|c|}{-988.17} & \multicolumn{2}{|c|}{-987.13} \\
\hline$\rho 2$ & \multicolumn{2}{|c|}{0.484} & \multicolumn{2}{|c|}{0.484} \\
\hline
\end{tabular}


Table 4: MNL and RPL Model Estimates for Business Trips

\begin{tabular}{|c|c|c|c|c|}
\hline \multirow[b]{2}{*}{ Attribute } & \multicolumn{2}{|c|}{ MNL } & \multicolumn{2}{|c|}{ RPL } \\
\hline & Coefficient & Abs. t-ratio & Coefficient & Abs. t-ratio \\
\hline \multicolumn{5}{|l|}{ Random Parameters } \\
\hline Travel Time & -8.212 & 8.68 & -10.705 & 5.12 \\
\hline Service Headway & -0.074 & 4.75 & -0.080 & 3.28 \\
\hline Comfortable seating & 1.405 & 7.66 & 1.956 & 4.52 \\
\hline Part seating & 0.888 & 3.87 & 0.716 & 2.62 \\
\hline Comfortable standing & -1.154 & 2.52 & -0.789 & 1.40 \\
\hline \multicolumn{5}{|l|}{ Fixed Parameters } \\
\hline Travel Cost & -0.155 & 2.55 & -0.139 & 1.65 \\
\hline \multicolumn{5}{|c|}{ Random parameter spread } \\
\hline Travel Time & - & - & 10.705 & 5.12 \\
\hline Service Headway & - & - & 0.080 & 3.28 \\
\hline Comfortable seating & - & - & 1.956 & 4.52 \\
\hline Part seating & - & - & 0.716 & 2.62 \\
\hline Comfortable standing & - & - & 0.789 & 1.40 \\
\hline Observations & \multicolumn{2}{|c|}{332} & \multicolumn{2}{|c|}{332} \\
\hline Log Likelihood & \multicolumn{2}{|c|}{-161.77} & \multicolumn{2}{|c|}{-163.72} \\
\hline$\rho 2$ & \multicolumn{2}{|c|}{0.606} & \multicolumn{2}{|c|}{0.601} \\
\hline
\end{tabular}

Table 5: MNL and RPL Model Estimates for Job Trips

\begin{tabular}{|c|c|c|c|c|}
\hline \multirow[b]{2}{*}{ Attribute } & \multicolumn{2}{|c|}{ MNL } & \multicolumn{2}{|c|}{ RPL } \\
\hline & Coefficient & Abs. t-ratio & Coefficient & Abs. t-ratio \\
\hline \multicolumn{5}{|l|}{ Random Parameters } \\
\hline Travel Time & -5.699 & -10.63 & -6.620 & 8.12 \\
\hline Service Headway & -0.049 & -5.59 & -0.054 & 4.79 \\
\hline Comfortable seating & 0.999 & 7.56 & 1.213 & 6.55 \\
\hline Part seating & 0.573 & 4.07 & 0.486 & 3.14 \\
\hline Comfortable standing & -0.285 & -0.94 & -0.124 & 0.40 \\
\hline \multicolumn{5}{|l|}{ Fixed Parameters } \\
\hline Travel Cost & -0.073 & 1.68 & -0.055 & 1.91 \\
\hline \multicolumn{5}{|c|}{ Random parameter spread } \\
\hline Travel Time & - & - & 6.620 & 8.12 \\
\hline Service Headway & - & - & 0.054 & 4.79 \\
\hline Comfortable seating & - & - & 1.213 & 6.55 \\
\hline Part seating & - & - & 0.486 & 3.14 \\
\hline Comfortable standing & - & - & 0.124 & 0.40 \\
\hline Observations & \multicolumn{2}{|c|}{435} & \multicolumn{2}{|c|}{435} \\
\hline Log Likelihood & \multicolumn{2}{|c|}{-276.9} & \multicolumn{2}{|c|}{-278.4} \\
\hline$\rho 2$ & \multicolumn{2}{|c|}{0.502} & \multicolumn{2}{|c|}{0.500} \\
\hline
\end{tabular}


Table 6: MNL and RPL Model Estimates for Recreation Trips

\begin{tabular}{|c|c|c|c|c|}
\hline \multirow[b]{2}{*}{ Attribute } & \multicolumn{2}{|c|}{ MNL } & \multicolumn{2}{|c|}{ RPL } \\
\hline & Coefficient & Abs. t-ratio & Coefficient & Abs. t-ratio \\
\hline \multicolumn{5}{|l|}{ Random Parameters } \\
\hline Travel Time & -5.283 & 9.19 & -6.243 & 7.22 \\
\hline Service Headway & -0.046 & 5.11 & -0.051 & 4.38 \\
\hline Comfortable seating & 1.308 & 9.27 & 1.598 & 7.24 \\
\hline Part seating & 0.649 & 3.99 & 0.613 & 3.30 \\
\hline Comfortable standing & -0.290 & 0.96 & -0.080 & 0.25 \\
\hline \multicolumn{5}{|l|}{ Fixed Parameters } \\
\hline Travel Cost & -0.095 & 2.01 & -0.080 & 1.64 \\
\hline \multicolumn{5}{|c|}{ Random parameter spread } \\
\hline Travel Time & - & - & 6.243 & 7.22 \\
\hline Service Headway & - & - & 0.051 & 4.38 \\
\hline Comfortable seating & - & - & 1.598 & 7.24 \\
\hline Part seating & - & - & 0.613 & 3.30 \\
\hline Comfortable standing & - & - & 0.080 & 0.25 \\
\hline Observations & \multicolumn{2}{|c|}{360} & \multicolumn{2}{|c|}{360} \\
\hline Log Likelihood & \multicolumn{2}{|c|}{-238.8} & \multicolumn{2}{|c|}{-238.8} \\
\hline$\rho 2$ & \multicolumn{2}{|c|}{0.498} & \multicolumn{2}{|c|}{0.498} \\
\hline
\end{tabular}

Table 7: MNL and RPL Model Estimates for Education Trips

\begin{tabular}{|c|c|c|c|c|}
\hline \multirow[b]{2}{*}{ Attribute } & \multicolumn{2}{|c|}{ MNL } & \multicolumn{2}{|c|}{ RPL } \\
\hline & Coefficient & Abs. t-ratio & Coefficient & Abs. t-ratio \\
\hline \multicolumn{5}{|l|}{ Random Parameters } \\
\hline Travel Time & -4.570 & 5.73 & -5.022 & 4.87 \\
\hline Service Headway & -0.033 & 2.58 & -0.033 & 2.35 \\
\hline Comfortable seating & 1.215 & 5.75 & 1.396 & 4.80 \\
\hline Part seating & 0.463 & 2.08 & 0.451 & 1.84 \\
\hline Comfortable standing & -0.276 & 0.68 & -0.102 & 0.25 \\
\hline \multicolumn{5}{|l|}{ Fixed Parameters } \\
\hline Travel Cost & -0.115 & 2.19 & -0.112 & 1.98 \\
\hline \multicolumn{5}{|c|}{ Random parameter spread } \\
\hline Travel Time & - & - & 5.022 & 4.87 \\
\hline Service Headway & - & - & 0.033 & 2.35 \\
\hline Comfortable seating & - & - & 1.396 & 4.80 \\
\hline Part seating & - & - & 0.451 & 1.84 \\
\hline Comfortable standing & - & - & 0.102 & 0.25 \\
\hline Observations & \multicolumn{2}{|c|}{130} & \multicolumn{2}{|c|}{130} \\
\hline Log Likelihood & \multicolumn{2}{|c|}{-107.33} & \multicolumn{2}{|c|}{-107.46} \\
\hline$\rho 2$ & \multicolumn{2}{|c|}{0.367} & \multicolumn{2}{|c|}{0.366} \\
\hline
\end{tabular}


Table 8: MNL and RPL Model Estimates for Agricultural Trips

\begin{tabular}{|c|c|c|c|c|}
\hline \multirow[b]{2}{*}{ Attribute } & \multicolumn{2}{|c|}{ MNL } & \multicolumn{2}{|c|}{ RPL } \\
\hline & Coefficient & Abs. t-ratio & Coefficient & Abs. t-ratio \\
\hline \multicolumn{5}{|l|}{ Random Parameters } \\
\hline Travel Time & -5.091 & 6.33 & -5.476 & 5.31 \\
\hline Service Headway & -0.042 & 3.23 & -0.041 & 2.86 \\
\hline Comfortable seating & 1.039 & 5.41 & 1.171 & 4.60 \\
\hline Part seating & 0.558 & 2.71 & 0.525 & 2.29 \\
\hline Comfortable standing & -0.442 & 1.11 & -0.214 & 0.55 \\
\hline \multicolumn{5}{|l|}{ Fixed Parameters } \\
\hline Travel Cost & -0.173 & 2.58 & -0.148 & 2.27 \\
\hline \multicolumn{5}{|c|}{ Random parameter spread } \\
\hline Travel Time & - & - & 5.476 & 5.31 \\
\hline Service Headway & - & - & 0.041 & 2.86 \\
\hline Comfortable seating & - & - & 1.171 & 4.60 \\
\hline Part seating & - & - & 0.525 & 2.29 \\
\hline Comfortable standing & - & - & 0.214 & 0.55 \\
\hline Observations & \multicolumn{2}{|c|}{151} & \multicolumn{2}{|c|}{151} \\
\hline Log Likelihood & \multicolumn{2}{|c|}{-126.12} & \multicolumn{2}{|c|}{-127.09} \\
\hline$\rho 2$ & \multicolumn{2}{|c|}{0.363} & \multicolumn{2}{|c|}{0.359} \\
\hline
\end{tabular}

Table 9: MNL and RPL Model Estimates for Others’ Trips

\begin{tabular}{|c|c|c|c|c|}
\hline \multirow[b]{2}{*}{ Attribute } & \multicolumn{2}{|c|}{ MNL } & \multicolumn{2}{|c|}{ RPL } \\
\hline & Coefficient & Abs. t-ratio & Coefficient & Abs. t-ratio \\
\hline \multicolumn{5}{|l|}{ Random Parameters } \\
\hline Travel Time & -5.385 & 4.87 & -6.190 & 3.96 \\
\hline Service Headway & -0.043 & 2.34 & -0.042 & 2.09 \\
\hline Comfortable seating & 0.839 & 3.12 & 0.933 & 2.72 \\
\hline Part seating & 0.204 & 0.73 & 0.112 & 0.37 \\
\hline Comfortable standing & -0.290 & 0.53 & -0.059 & 0.11 \\
\hline \multicolumn{5}{|l|}{ Fixed Parameters } \\
\hline Travel Cost & -0.18 & 1.95 & -0.163 & 1.76 \\
\hline \multicolumn{5}{|c|}{ Random parameter spread } \\
\hline Travel Time & - & - & 6.190 & 3.96 \\
\hline Service Headway & - & - & 0.042 & 2.09 \\
\hline Comfortable seating & - & - & 0.933 & 2.72 \\
\hline Part seating & - & - & 0.112 & 0.37 \\
\hline Comfortable standing & - & - & 0.059 & 0.11 \\
\hline Observations & \multicolumn{2}{|c|}{81} & \multicolumn{2}{|c|}{81} \\
\hline Log Likelihood & \multicolumn{2}{|c|}{-70.78} & \multicolumn{2}{|c|}{-70.69} \\
\hline$\rho 2$ & \multicolumn{2}{|c|}{0.281} & \multicolumn{2}{|c|}{0.282} \\
\hline
\end{tabular}


Willingness-to-Pay Values

Table 10: WTP Values of Attributes for Different Trip Purposes

\begin{tabular}{lcccccccccc}
\hline Attributes & \multicolumn{1}{c}{$\begin{array}{c}\text { Travel Time } \\
\text { Paise**/min }\end{array}$} & $\begin{array}{c}\text { Headway * } \\
\text { Paise/min }\end{array}$ & $\begin{array}{c}\text { Comfortable } \\
\text { seating } \\
\text { Paise/km }\end{array}$ & $\begin{array}{c}\text { Part } \\
\text { seating } \\
\text { Paise/km }\end{array}$ & $\begin{array}{c}\text { Comfortable } \\
\text { standing } \\
\text { Paise/km }\end{array}$ \\
\hline MNL & $R P L$ & MNL & $R P L$ & MNL & $R P L$ & MNL & $R P L$ & MNL & $R P L$ \\
1. Total Sample & 53.66 & 76.60 & 20.50 & 26.94 & 24.37 & 37.02 & 18.10 & 25.46 & 8.70 & 17.13 \\
2. Business & 52.90 & 77.05 & 19.34 & 23.50 & 16.39 & 27.63 & 13.06 & 18.71 & 0.09 & 7.88 \\
3. Job & 77.86 & 121.23 & 32.23 & 47.93 & 31.22 & 51.05 & 25.40 & 37.73 & 13.68 & 26.57 \\
4. Recreation & 55.58 & 78.29 & 27.86 & 36.77 & 31.30 & 46.77 & 24.37 & 34.42 & 14.49 & 25.73 \\
5. Education & 39.63 & 44.66 & 9.83 & 10.27 & 22.69 & 27.92 & 16.17 & 19.52 & 9.77 & 14.60 \\
6. Agriculture & 29.38 & 37.11 & 9.26 & 10.55 & 12.67 & 17.97 & 9.89 & 13.59 & 4.12 & 8.58 \\
7. Others & 29.90 & 38.08 & 11.46 & 12.37 & 8.84 & 11.81 & 5.31 & 6.76 & 2.57 & 5.71 \\
\hline
\end{tabular}

* values are for average trip length of respective trips ** 100 paise $=1$ INR and 44 INR $=$ US \$1

\section{CONCLUSIONS}

For judicious improvement planning of rural bus service and evaluation of user benefits, it is necessary to estimate users' WTP values. In the present paper, WTP values associated with different attributes of rural bus service are estimated in a developing country context. Using stated choice data, both MNL and RPL models are developed and WTP values associated with travel time, comfort, and headway are estimated for all trip purposes as well as for different trip purposes. The estimated WTP values are found to be significant and in agreement with the actual conditions of the study route.

It is observed that trip makers' marginal WTP is not the same for all attributes of travel, and the WTP values also vary with trip purpose. The WTP values associated with comfort and travel time are higher for job trips. Recreational trip makers value travel time, comfort and headway slightly less than job trip makers, but more than business trip makers. The WTP values associated with job, business, and recreational trips are more than those for education, agriculture, and other trips.

A comparison of WTP values produced by the MNL and RPL models developed in the present study reveals that estimates from the MNL model are generally lower than those of the RPL model. In general, use of RPL models should be encouraged for estimating WTP values as they relax the restrictions imposed by MNL. Though contextual, the results presented here can be valuable inputs to policy makers for improvement planning of bus services in rural areas of developing countries.

\section{References}

Adamowicz, W. L., J. Louviere, and M. Williams. "Combining Stated and Revealed Preference Methods for Valuing Environmental Amenities." Journal of Environmental Economics and Management 26, (1994): 271-292.

Algers. S, P. Bergström., Matz Dahlberg, and L. D. Johanna. "Mixed Logit Estimation of the Value of Travel Time.” Working paper series, Department of Economics, Uppsala University, Sweden, 1998.

Bates, J. “Stated Preference Technique for the Analysis of Transportation Behavior.” In Proceedings of World Conference of Transportation Research, Hamburg, W. Germany, (1982): 252-265. 
Ben-Akiva, M. and S.R. Lerman. Discrete Choice Analysis: Theory and Applications to Travel Demand. MIT Press, Cambridge, 1985.

Bhatt, C. "Accommodating Variations in Responsiveness to Level-of-service Measures in Travel Mode Choice Modeling.” Transportation Research 32A, (1998): 495-507.

Carlsson, F. "The Demand for Intercity Public Transport: The Case of Business Passengers." Working Paper, Department of Economics, Göteborg University, 1999.

Carlsson, F., P. Frykblom, and C. Liljenstolpe. "Valuing Wetland Attributes: An Application of Choice Experiments.” Ecological Economics 47, (2003): 95-103.

Cherchil, E. and J. W. Polak. "The Assessment of User Benefits Using Discrete Choice Models: Implications of Specification Errors Under Random Taste Heterogeneity.” Prepared for presentation at 85th annual Meeting of the Transportation Research Board, Washington, D.C., January 2005.

Farhad Ahmed and Kirit G Vaidya. "The Valuation of Travel Time Savings in Least Developed Countries: Theoretical and Empirical Challenges and Results from a Field Study.” In the Proceedings of World Conference of Transportation Research, Istanbul, Turkey, 2004.

Greene, W. H. LIMDEP Version 8.0: Econometric Modeling Guide. Econometric Software Inc, Plainview, New York, 2002.

Greene, W. H., D.A. Hensher, and John Rose. "Accounting for Heterogeneity in the Variance of Unobserved Effects in Mixed Logit Models.” Transportation Research B, (2005): In press.

Hensher, D.A. "Stated Preference Analysis of Travel Choices: The State of Practice.” Transportation 21(2), (1994): 107-133.

Hensher, D. A. "The Valuation of Commuter Travel Time Savings for Car Drivers in New Zealand: Evaluating Alternative Model Specifications.” Transportation 28, (2001a): 101-118.

Hensher D. A. "Measurement of the Valuation of Travel Time Savings.” Journal of Transport Economics and Policy 35 (1), (2001b): 71- 98.

Hensher, D. A. and W.H. Greene. "The Mixed Logit Model: The State of Practice and Warnings for the Unwary.” Working Paper, School of Business, The University of Sidney, 2001.

Hensher, D A and C. Sullivan. “Willingness to Pay for Road Curviness and Road Type.” Transportation Research Part D 8, (2003): 139-155.

Hensher, D A. John M. Rose, and W.H. Greene. Applied Choice Analysis: A Primer. Cambridge University Press, 2005.

Hess, S., M. Bierlaire, and J.W. Polak, "Estimation of Value of Travel-time Savings Using Mixed Logit models.” Transportation Research A, 3-39, (2005): 221-236.

I. T. Transport, “The Value of Time in Least Developed Countries: The African Studies.” Unpublished Report, I. T Transport Ltd., United Kingdom, 2005.

Jose Holguin-Veras, P. E. "Revealed Preference Analysis of Commercial Vehicle Choice Process." Journal of Transportation Engineering 128 (4), (2002): 236-346.

Kroes, E.P. and R.J. Sheldon. "Stated Preference Methods: An Introduction.” Journal of Transport Economics and Policy 22, (1988): 11-25.

Kumarage, A. "Impact of Transport Infrastructure \& Services on Urban Poverty and Land Development: A Case Study - Colombo, Sri Lanka.” presented at World Bank symposium 2005. <www.worldbank.org/urban/symposium2005/presentations/Kumarage.pdf> accessed February, 2006. 
Willingness-to-Pay Values

Louviere, J.J. "Conjoint Analysis Modeling of Stated Preferences: A Review of Theory, Methods, Recent Developments and External Validity.” Journal of Transport Economics and Policy 22(1), (1988): 93-119.

Louviere, J.J., D.A. Hensher, and D.J. Swait. Stated Choice Methods. Analysis and Applications. Cambridge University Press, 2000.

McFadden, D. “Conditional Logit Analysis of Qualitative Choice Behavior.” P. Zarembka ed. Frontiers in Econometrics. New York: Academic Press (1974): 105-142.

Mumbai Metro Planning Group (MMPG). "Mumbai Metro Study: Travel Demand Forecasting Model.” Working Paper No. 4, Mumbai,1997.

Onyango, Benjamin, Ramu Govindasamy, and Rodolfo M. Nayga, Jr. "Measuring U.S. Consumer Preferences for Genetically Modified Foods Using Choice Modeling Experiments: The Role of Price, Product Benefits and Technology.” Paper prepared for presentation at the American Agricultural Economics Association Annual Meeting, Denver, Colorado, August 2004.

Praveen, K. S. and K.V.K. Rao. "Estimation of Passenger Demand on a Proposed Passenger Water Transport System.” Proceedings of Transportation Planning and Methodologies for Developing Countries, IITBombay, Mumbai, 2002.

Thurstone, L. L. “A Law of Comparative Judgment.” Psychological Review 4, (1927): 273-286.

Train, K. "Recreation Demand Models with Taste Differences Over People.” Land Economics (1998): 230-239.

Train. K, "Halton Sequences for Mixed Logits.” Working Paper, Department of Economics University of California at Berkeley, 1999.

\section{Acknowledgments}

The work presented in the paper is based on the research project sponsored by the Department of Science and Technology (DST), Ministry of Science and Technology, Government of India.

C.V. Phanikumar is a research scholar in transportation engineering, department of civil engineering at Indian Institute of Technology Kharagpur, India. His research interests include transport economics, transport planning and framing-related policy issues using behavioral analysis. He has experience in geometric design of highways and traffic engineering.

Bhargab Maitra obtained his Ph.D. from IIT, Bombay, India, and is presently an assistant professor in transportation engineering, department of civil engineering at Indian Institute of Technology, Kharagpur. His research interests include traffic management, operation and maintenance, congestion modeling, and improving public transport systems using behavioral analysis. He has published numerous papers in both national and international journals. 